\title{
General Chemistry for Students Enrolled in a Life Sciences Curriculum
}

\author{
Jean-Claude G. Bünzlia ${ }^{a}$, Emmanuel Fernandes ${ }^{b}$, Daniel Imberta, Anne-Sophie Chauvin ${ }^{\mathrm{a}}$, \\ Franzpeter Emmenegger ${ }^{c}$, Cédric Rauzyc, Claude Piguet ${ }^{d}$, Nadjet Oualid, Sylvain Koeller ${ }^{d}$, \\ Georg Süss-Fink ${ }^{\mathrm{e}}$, and Frédéric Chérioux ${ }^{\mathrm{e}}$
}

\begin{abstract}
The goal of this three-year project is to establish a modular and interactive Internet website for the teaching of general chemistry to freshmen students enrolled in a life sciences university program (medicine, biology, possibly pharmacy). Students should become familiar with the basic chemistry concepts needed to understand important life processes and the whereabouts in day-to-day usage of chemical technologies. The idea behind the project, supported by four partner universities (Geneva, Lausanne, Neuchâtel, Fribourg), is to offer a flexible tool to students who have followed very different secondary education programs, some of them having not yet taken any science course. The project aims therefore at optimizing their basic science training during the first year of higher education. A system of online exercises and tests helps the students to assess their understanding of the matter. Video films of live experiments and computer simulations illustrate the main principles and phenomena described in the teaching program. Whenever possible, the teaching aims at an integrated vision of biosciences, as illustrated by some examples using a problem-based approach. The site will offer bilingual (French, English), possibly trilingual (German), teaching and is intended to serve annually 1200-1300 students from the supporting universities.
\end{abstract}

Keywords: e-Learning · General chemistry · Online teaching

\section{Origin of the Project}

Chemistry is one of the four natural sciences and its teaching is included in the program of most of the students enrolled in a sciences or life sciences curriculum. At many universities, general chemistry, a field aiming at teaching the basic principles of chemistry, is the subject of a specially

\footnotetext{
${ }^{*}$ Correspondence: Prof. J.-C.G. Bünzlia

Tel.: +41216939821

Fax: +41216939825

E-Mail: jean-claude.bunzli@epfl.ch

aÉcole Polytechnique Fédérale de Lausanne, Institut de chimie moléculaire et biologique, BCH-LCSL, CH-1015 Lausanne

bProject co-ordinator, Université de Lausanne, Centre des technologies pour l'enseignement et la formation (CENTEF), Bâtiment Provence, $\mathrm{CH}-1015$ Lausanne

cUniversité de Fribourg, Département de chimie, Université-Pérolles, $\mathrm{CH}-1700$ Fribourg

dUniversité de Genève, Département de chimie minérale, analytique et appliquée,

30 quai Ernest Ansermet, $\mathrm{CH}-1211$ Genève-4

eUniversité de Neuchâtel, Institut de chimie,

Avenue de Bellevaux 51, CH-2000 Neuchâtel
}

tailored program for life sciences (medicine, biology, pharmacy) students. Two main reasons prevail for explaining such a pedagogic choice. Firstly, the number of students is large and has been constantly growing over the last years: presently, more than 800 students in medicine and biology take the magisterial general chemistry courses offered in Geneva and Lausanne. Secondly, these students have specific needs with respect to their future professional involvement which can only be taken into consideration within a targeted teaching. At the universities of Neuchâtel (100 students in life sciences) and Fribourg (150 students in life sciences), the situation is somewhat different and only one course in general chemistry is offered to the students in both sciences and life sciences.

Optimizing such a teaching program is rather challenging, with respect to both the intrinsic needs of a branch (chemistry) which requires numerous exercises and laboratory practice in order to be fully understood, and the specific needs of the students. In addition, regulations at the partner institutions allow any student with any high-school diploma ('maturité') to enroll in any higher education program. In addition recent profound changes have been implemented in the programs of secondary education resulting in more and more freshmen students arriving at university without having ever taken a chemistry introductory course, while others are already quite familiar with the basics of this branch. The stringent budgetary restrictions imposed during the 1990s have worsened the situation and have resulted in lower teacher-to-student ratios. The consequences of these restrictions are orthogonal to a pedagogic will which progressively gains ground within the Swiss medicine faculties, namely to move towards a more personalized teaching based on a problem-orientated approach, implying a tutoring system and very well-targeted pedagogic objectives.

This situation urged the partner professors from the universities of Geneva, Lausanne [1], Neuchâtel, and Fribourg to submit a three-year project within the frame of the Swiss Virtual Campus, which was accepted in June 2000, started on October 1 st 2000 and which is scheduled to end on December 31st, 2003. 


\section{Overall Concept}

In view of the diversity of the pedagogic approaches at the participating universities due to the different categories of students attending the courses and to the different numbers of hours allotted to the teaching (see Table), the initial idea has been to establish, as a first step, an interactive website featuring the basic information required to understand the subject matter taught at the partner institutions. That is, the website is meant to be (i) a support for the ex cathedra teaching and (ii) an aid for the students' self-study and exam preparation. Therefore the site must be flexible and modular so that each teacher and learner can use it according to his/her specific needs.

The second step aims at developing a more integrated pedagogic approach, with a reduction of the number of contact (ex cathedra) hours (ca. $25 \%$ ) for the benefit of creating exercises in small groups and of interactive learning. A more distant objective is a totally integrated approach allowing students (e.g. disabled students or people involved in other activities and desiring to acquire a second education) to take the interactive teaching and the exam from a distant location and therefore to get the corresponding number of ECTS credits.

\section{Working Concepts}

Given these ideas, the following working concepts have been adopted.

(a) The course is divided into twelve independent modules describing and illustrating the fundamental principles of general chemistry, theme by theme, subject by subject, in order to allow each teacher of the partner universities to refer to these modules while arranging them in the order corresponding to his pedagogic approach. A list of these modules is given below with, between parentheses, the university in charge of it.

1. Chemistry and life sciences (UNIL)

2. Matter and chemistry (UNIFR)

3. The chemical reaction (UNIGE)

4. Proton transfer reactions (UNIL)

5. Electron transfer reactions (UNINE)

6. Ligand transfer reactions (UNIFR)

7. Chemical kinetics (UNIL)

8. The chemical bond (UNIGE)

9. Intermolecular interactions (UNIGE)

10. Solution properties (UNIGE)

11. Analytical methods (UNIL)

12. Nuclear reactions (UNINE)

(b) In view of the differences in the learner populations at the various campuses, each module contains two levels. The first one is directly accessible and rep-

Table. Present allotment (hours) for general chemistry at the various partner universities (academic year 2002/2003).

\begin{tabular}{lllccc} 
University & $\begin{array}{l}\text { Categories } \\
\text { of students }\end{array}$ & $\begin{array}{l}\text { Ex cathedra } \\
\text { course }\end{array}$ & Exercises & $\begin{array}{c}\text { Practical } \\
\text { teaching }\end{array}$ & Total \\
\hline Genève & Medicine & 52 & 16 & 36 & 104 \\
& Biology & 78 & 16 & 36 & 130 \\
Lausanne & Medicine & 54 & 8 & 48 & 110 \\
& Biology & 54 & 18 & 52 & 124 \\
Neuchâtel & Medicine & 56 & 28 & 72 & 156 \\
& Biologya & 84 & 42 & 100 & 226 \\
Fribourg & Medicine & 38 & $26^{\mathrm{b}}$ & 36 & 100 \\
& Biology & 54 & $26^{\mathrm{b}}$ & 36 & 116
\end{tabular}

a General and analytical chemistry; general chemistry: 56 h course, 28 h exercises.

b Optional tutorial

resents the basic matter for the life sciences students. The second level, meant as an addition for the chemistry students, is accessible through special windows indicated by (2); whenever needed, entire paragraphs belong to this second level.

(c) The chapter contents are illustrated by examples inspired from situations found in day-to-day life or in biology and medicine. In addition, the subjects are made more attractive by inserting especially created animations (using the Macromedia ${ }^{\circledR}$ Flash $^{\text {TM }} 5$ program) and video films; the latter being either bought from other authors or created at the University of Neuchâtel by Prof. G. Süss-Fink. However, the first version of the course will have a minimum number of these illustrations in order to make it available online as soon as possible.

(d) At the end of each module, series of exercises are proposed, with an increasing level of difficulty. Hints and complete answers are provided, as well as links to the relevant part of the module. In addition, questions in the style of the specific exam at each partner institution are also on hand so that the students can evaluate their knowledge and get acquainted with the form of the exam. For this purpose, a special platform, Ariadne ${ }^{\circledR}$, developed by the CENTEF and other partners is used. Again, the first version of the course will feature a minimum number of exercises, but in the final version, this aspect will be developed so that student can better self-evaluate their knowledge and, in a final stage, be assessed directly online by their tutors.

(e) Two printed versions of each module are available, one comprised of the first level only and the other featuring both levels.

(f) The modules have been written in French initially and will then be translated into English and, time permitting, into German.

\section{Project Management}

The professors and the project co-ordinator are members of a steering committee which meets regularly every three-to-four months to decide upon the main strategy of the project, both on the academic and the organizational level. The role of the coordinator is to provide a link between this committee, the assistants (up to six have been working for the project, several of them part time) and the supporting offices from the leading house, the University of Lausanne (CENTEF and computing center). He also proposes the software and the technical solutions needed to design the pages, makes sure that the assistants are trained to use it (by their own institutions), and designs the standardized model of the pages used by all the partners (including a graphic toolbox). A typical flow chart for the production of a module is described on Fig. 1. The designated professor (sometimes with the help of his assistants) writes a first draft of the module, which is then sent to the other partner for comments and additions. Once a final version is agreed upon, it is transferred to the assistants who translate the text and graphic files into web pages which are stored onto a working server accessible by all the assistants. After careful re-reading of the subject, the project co-ordinator transfers it onto the official website of the course.

\section{Description of the Modular Site}

The website of the course is accessible through the CENTEF website at http://www. centef.ch/chimie. The trilingual (French, German and English) presentation of the course is open to the general public, while the course itself can only be accessed by the 

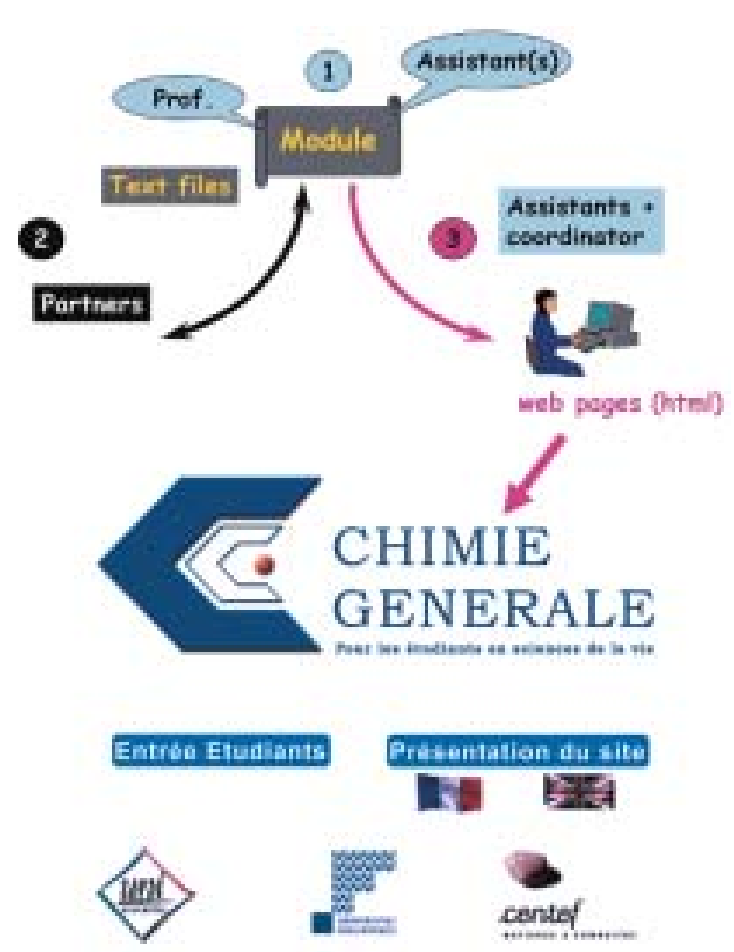

Fig. 1. Scheme showing the steps involved in the production of a module. students enrolled at the four partner universities, with a proper username and password. Modalities for further access by other students or interested people are presently under discussion within the Swiss Virtual Campus.

The presentation of the course starts with a discussion of the biology-chemistry interface with the breathing process as an example (see next section) then by an overview of the site describing the main features found in the various modules. It also features a table of contents listing all the modules and presenting three typical pages of each module as well as, whenever relevant, the link to the breathing process.

Each module of the course starts with a banner page with motivations and pedagogic objectives. The standard page of the modules (Fig. 2) features a wide left margin with a dynamic scroll menu allowing the student to reach rapidly the section he/ she wants to study; otherwise the learner can simply use the navigation buttons. The header contains the titles of the module, chapter and section, for an easy identification of the current page. There are also sev-

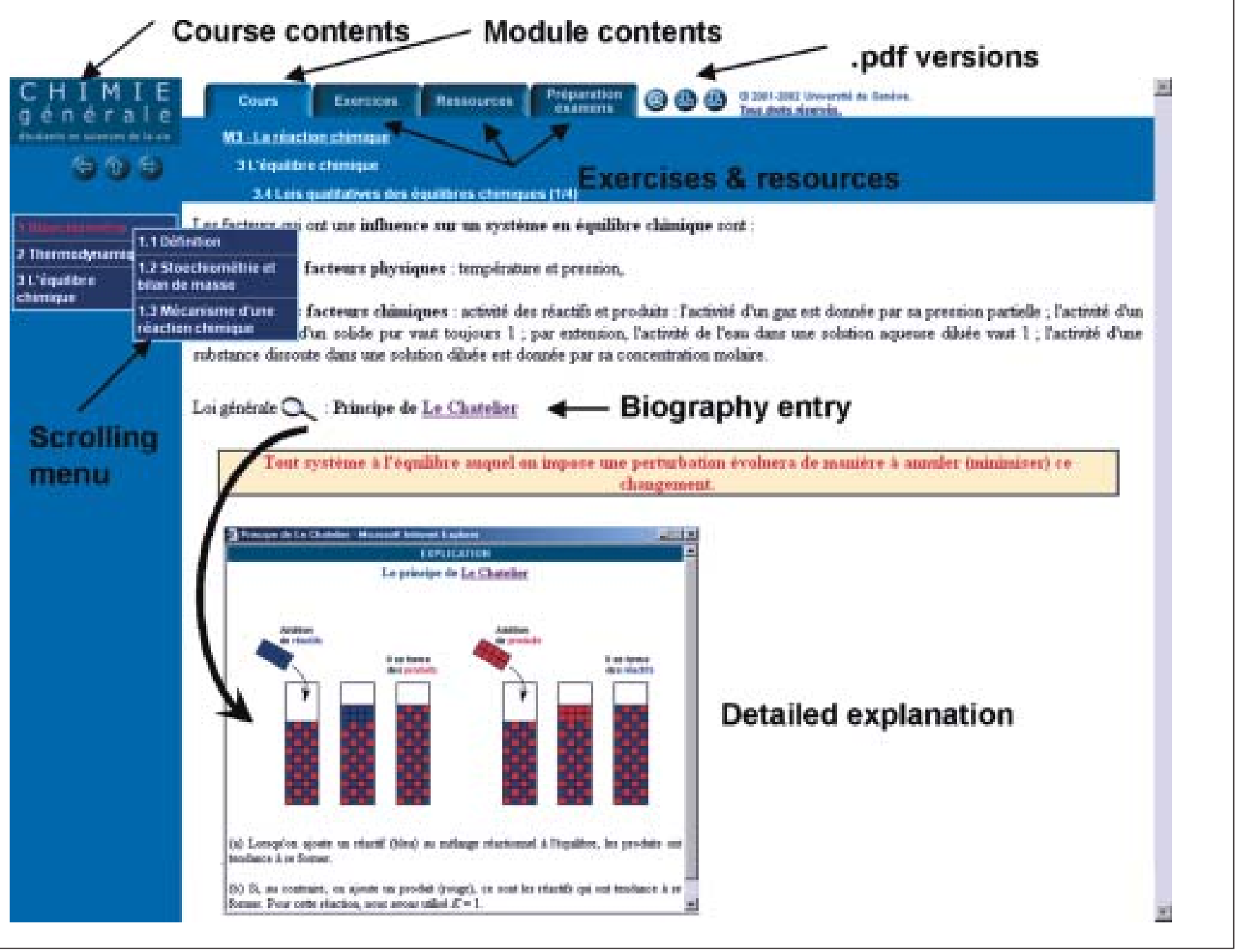

Fig. 2. Typical layout of a page (Module Chemical reaction). 
eral buttons allowing the student to reach (i) other modules of the course ('Chimie générale'), (ii) the table of contents of the module ('Cours'), (iii) exercises ('Exercices'), (iv) other resources ('Ressources') such as an integrated index, useful links, a search engine, a connection to the forum (to

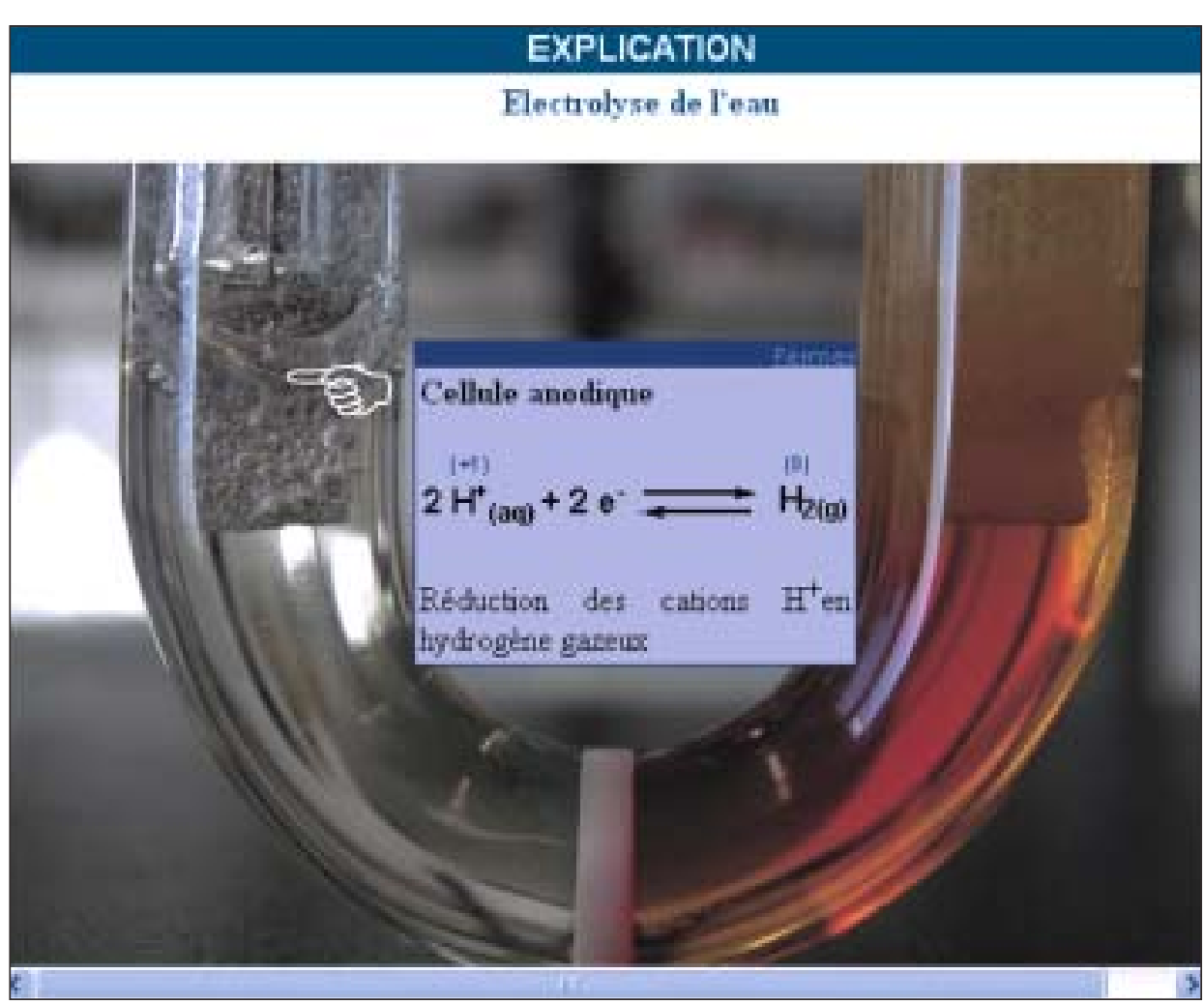

Fig. 3. Self-explanatory figure (Water electrolysis, Module Electron transfer reactions).

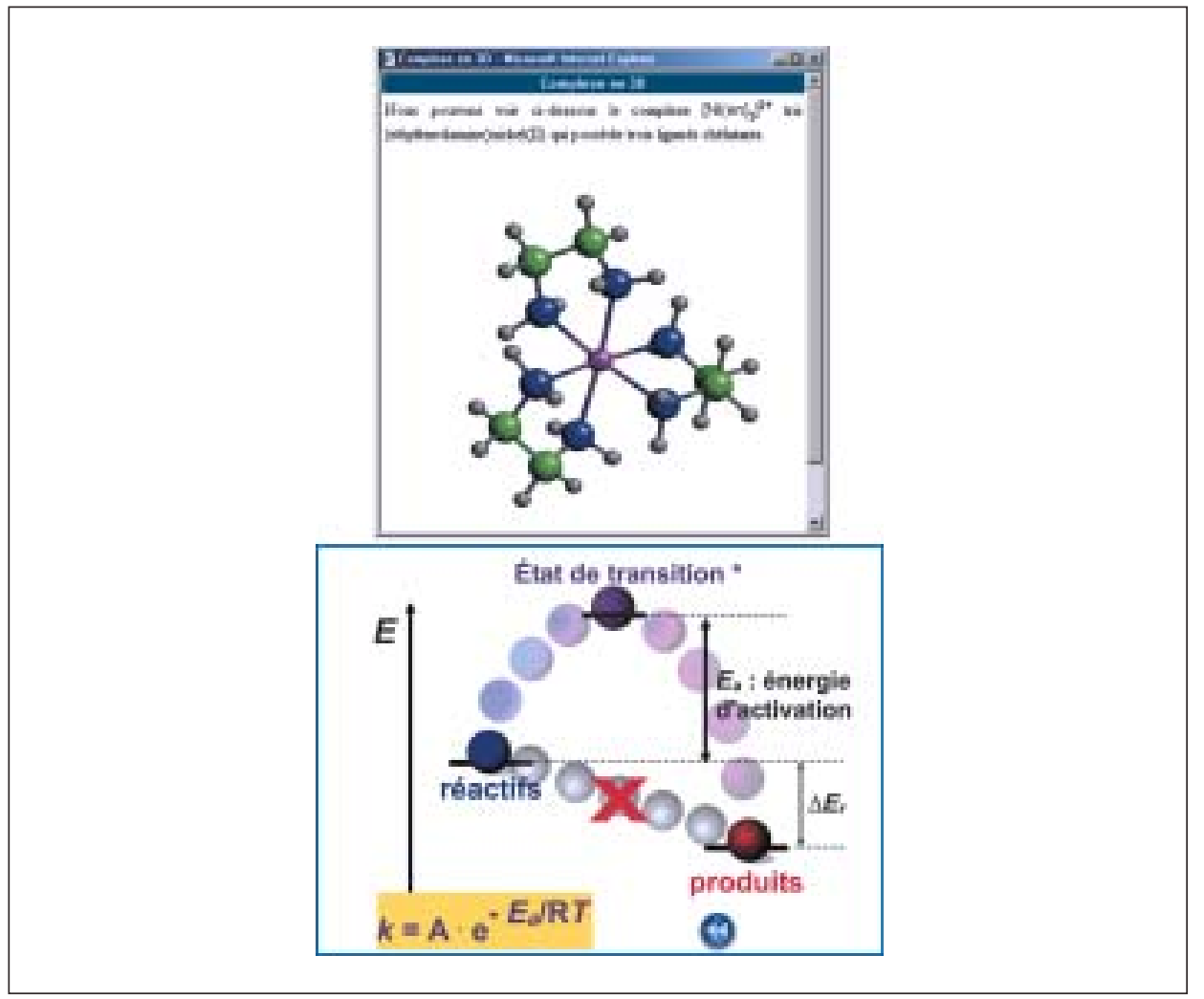

Fig. 4. (Top) Ball and stick animated model of a co-ordination compound (Module Ligand transfer reactions); (bottom) final status of a Flash animation (Module Chemical kinetics). is indicated either by $Q$ or (second level). Among further resources meant to help the student figure out the subject matter more easily, we note photographs of experiments with dynamic explanations (relevant information appearing when the mouse pointer is brought into a specific region of the illustration, see Fig. 3), rotating 3D pictures of molecules (Fig. 4, top), Flash $^{\mathrm{TM}}$ animations (Fig. 4, bottom), and the above-mentioned video films (Fig. 5). Finally, the biography of the cited chemists and other scientists is also available online.

\section{An Integrated Approach for the Teaching of Natural Sciences}

An example aimed at demonstrating the role of chemistry in life sciences processes is shown on the public presentation of the site. The mechanism of human breathing has been chosen as a typical example (Fig. 6) because it allows one to draw obvious links between the basic knowledge in chemistry and the concepts needed to understand this phenomenon.

The first step in the process is the inhalation of air (see (1) on Fig. 7). The module Matter and chemistry introduces notions such as partial pressures and solubility of gases in liquids needed to understand how gaseous exchanges take place in the body, for instance between oxygen and carbon dioxide at the level of the lungs. The blood arriving in the lungs possesses a weaker partial pressure in oxygen $\left(\mathrm{PO}_{2}\right)$ and a higher partial pressure in carbon dioxide $\mathrm{PCO}_{2}$ compared with their respective partial pressures in the lungs. Carbon dioxide diffuses from the blood to the lungs while oxygen diffuses from the lungs into the blood. At the tissue level, the phenomenon is inverted. The oxygen is then carried into the blood by a protein called hemoglobin which binds the oxygen, and releases it at the tissue level. Hemoglobin then returns to the lungs to repeat the cycle. The hemoglobin molecule contains four heme units

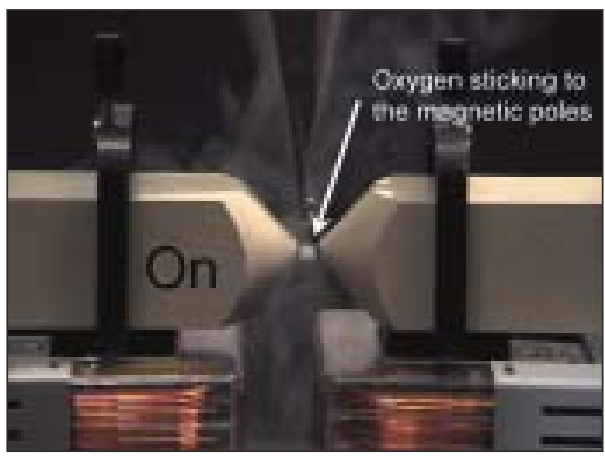

Fig. 5. The proof that oxygen is a paramagnetic di-radical (from a video sequence). 


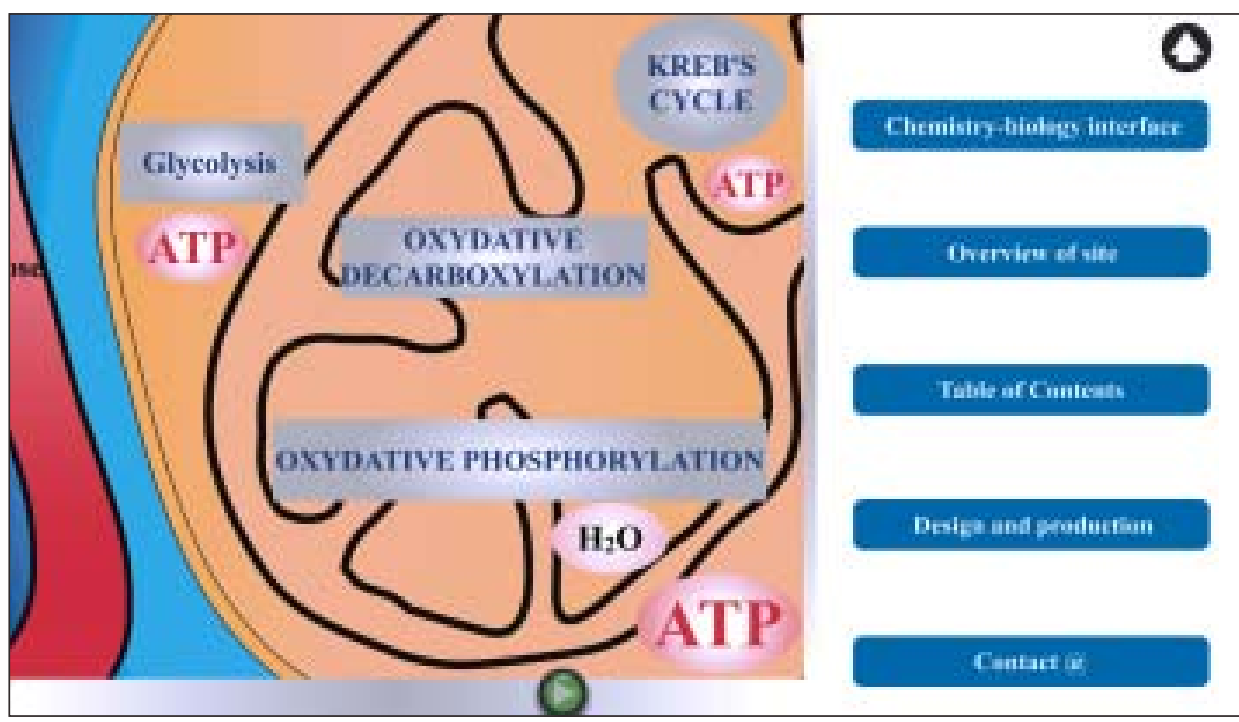

(see (2) on Fig. 7), each featuring a central iron ion onto which one oxygen molecule binds by a process described in the module Ligand transfer reactions (3) on Fig. 7). Each molecule of hemoglobin is thus capable of carrying four molecules of oxygen. The various types of chemical bonds implied in the oxygenated and de-oxygenated forms of hemoglobin are described in the modules The chemical bond and Intermolecular interactions.

The subsequent steps of the process take place in the cells. The latter are places where thousands of synthetic and degrada- tion reactions occur simultaneously; they are also the places where the human being produces the energy necessary for his survival, typically by extracting it from energetic molecules, such as glucose, through an oxidation process triggered by oxygen. Cellular breathing is comprised of three metabolic processes: glycolysis, the Kreb's cycle and the oxidative phosphorylation. Glycolysis degrades glucose (or other similar organic molecules), producing two moles of pyruvate per mole of glucose while the Kreb's cycle transforms derivatives of pyruvate into carbon dioxide. Several steps
Fig. 6 Website presentation: the chemistrybiology interface.

of these two processes are redox reactions which transfer electrons from the nutrient to the oxidized form of nicotinamide adenine dinucleotide, $\mathrm{NAD}^{+}$, yielding the reduced form $\mathrm{NADH}$ and $\mathrm{H}^{+}$. Here, there is an obvious connection with the module Electron transfer reactions. During these stages, firstly pyruvate and then the acetyl coenzyme A are synthesized by successive chemical reactions such as those described in the module The chemical reaction. This module also deals with the energetics of the chemical reactions, an aspect essential to the processes we are describing. In fact, the energy needed by various reactions in the cell mostly comes from the transformation of adenosine triphosphate (ATP) into adenosine diphosphate (ADP). After the Kreb's cycle is completed, carbon dioxide is produced and must be released from the body. It diffuses outside the cells into the blood plasma and into erythrocytes where it is transformed into carbonic acid $\mathrm{H}_{2} \mathrm{CO}_{3}$ by an enzyme called carbonic anhydrase (see (4) on Fig. 7). At this level, concepts presented in the module Chemical kinetics are very useful to the understanding of the increase of reaction rates by enzymes. Furthermore, the module Proton transfer reactions gives

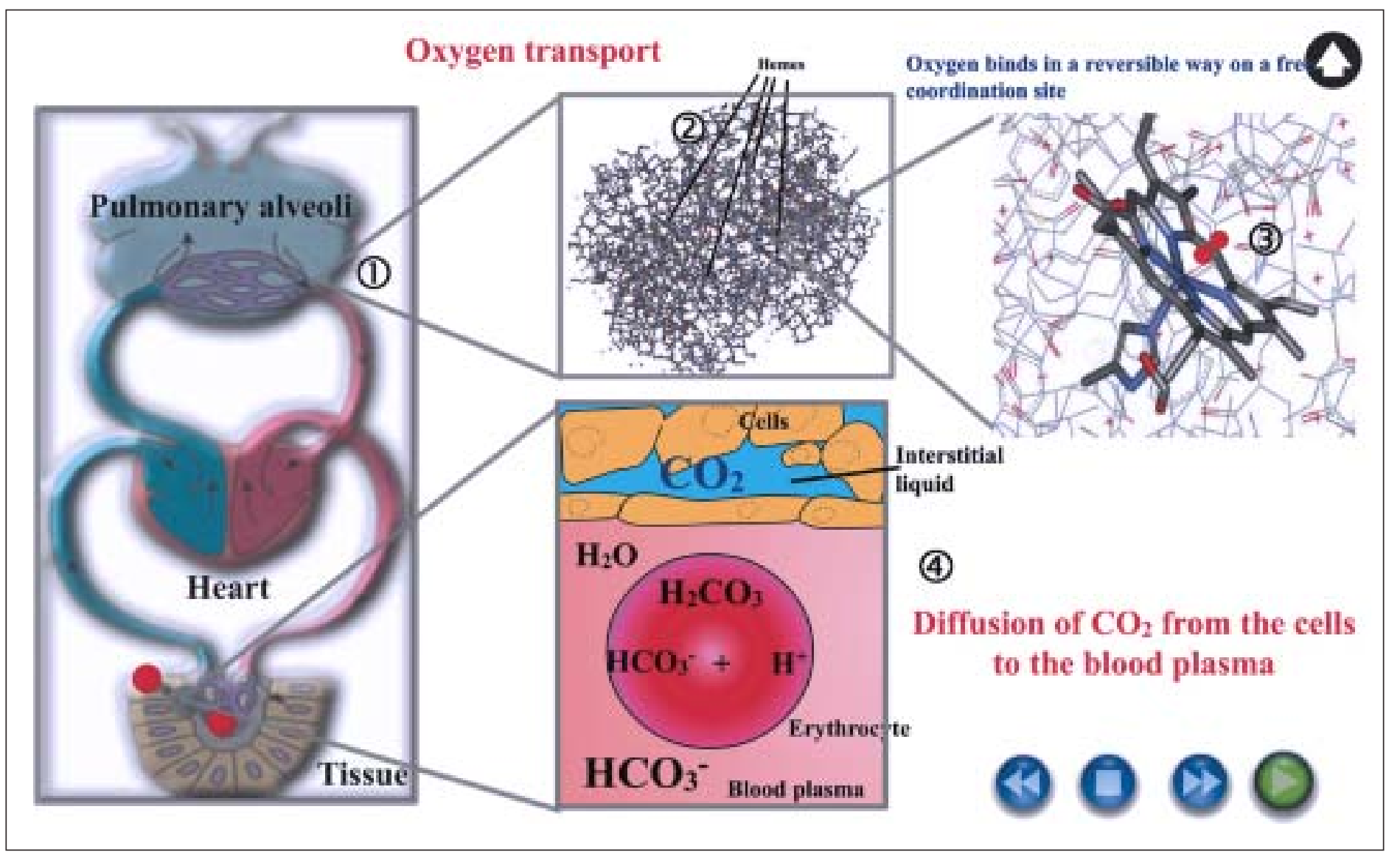

Fig. 7. The breathing phenomenon (website presentation). 
clues for the understanding of several phenomena related to the dissociation reaction of carbonic acid $\mathrm{H}_{2} \mathrm{CO}_{3}$ into hydronium $\left(\mathrm{H}_{3} \mathrm{O}^{+}\right)$and hydrogenocarbonate $\left(\mathrm{HCO}_{3}{ }^{-}\right)$ ions (see (4) on Fig. 7). The reversibility of the carbon dioxide transformation into $\mathrm{HCO}_{3}{ }^{-}$contributes to the buffering of the blood (releasing or eliminating $\mathrm{H}_{3} \mathrm{O}^{+}$to maintain a constant $\mathrm{pH}$ value of 7.4), an essential process also described in this module. These processes which take place at the level of tissues are upturned in the lungs; carbon dioxide being released and then diffusing outside the blood into the lungs before being expelled from the body.

In the last metabolic process of the cell breathing (oxidative phosphorylation), oxygen is used as the final acceptor of electrons during the formation of ATP. This stage takes place inside the mitochondria, at the level of the inner mitochondrion membrane. A trans-membrane concentration gradient of protons producing an electric potential is responsible for the final energy storage, a phenomenon explained in the module Solution properties. The oxidative phosphorylation involves numerous chemical reactions which occur in the human body, the electron transfer reactions (see again the corresponding module). The electron transport chain ultimately produces water through reduction of oxygen. Electrons are transferred by $\mathrm{NADH}+\mathrm{H}^{+}$to the first molecule, then every molecule in the electron transport chain oscillates between the reduced and oxidized states until the electrons reach the final acceptor molecule, oxygen.

In conclusion, understanding the breathing phenomenon requires the knowledge of nine modules of the course.

Another example of the integration of chemistry into natural and biomedical sciences could be the design of a contrast agent for medical imaging. The challenge here is the introduction of a highly toxic substance (namely the gadolinium trivalent ion, $\mathrm{Gd}^{3+}$ ) into human body to shorten the relaxation time of hydrogen nuclei excited by a radiofrequence radiation. The trick is to insert this ion into a receptor which tightly binds it so that it cannot be released into the body. Understanding the design of such a metal complex and the phenomena leading to contrast enhancement of the medical image requires the knowledge described in at least seven modules of the course.

\section{Pedagogic Approach}

The presently in-built pedagogic aspect of the project is the use of the Ariadne ${ }^{\circledR}$ platform to design the multiple choice ques-

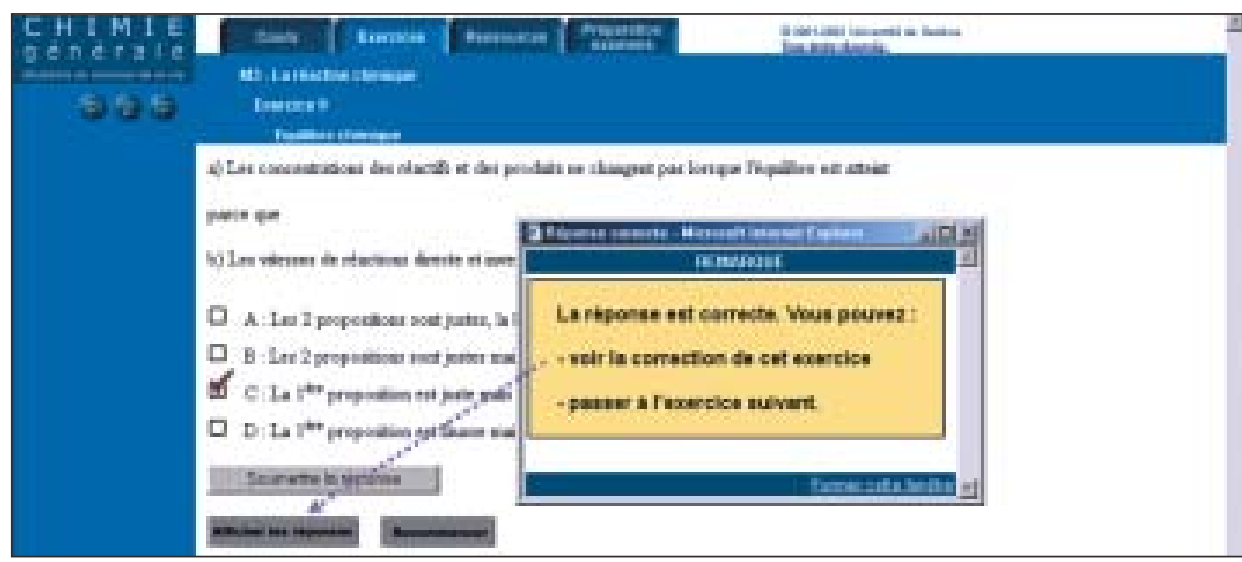

Fig. 8. Typical layout of an exercise page.

tions at the end of each module (Fig. 8). Moreover, the project is being monitored by Dr. Jacques Viens from the TECFA unit (Technologies de formation et apprentissage) of the University of Geneva (contracted by the Swiss Virtual Campus, project IntersTICES) who has identified several actions to be taken in order to improve the relationship between the subjects, the learners and the teachers; for instance, a forum will be established, as well as concise guides for the utilization of each module. On the longer term, a more adapted pedagogic scenario will be developed, allowing a more efficient use of the online facilities, based on the results of a questionnaire distributed to the students from Lausanne University (December 2002).

\section{Present Status and Perspectives}

At present, eight out of the twelve modules have been completed and are online, most of them with a first series of exercises. These modules represent the core of the course. The last four modules are scheduled to be online by June 2003. The site has now been opened to the students of the four partner universities and we are gathering the first comments [2]. It is noteworthy that before November 2002, a total of about one hundred visits to the site were recorded. Since the beginning of the academic year, the number of visits has reached almost one hundred a day. A detailed monitoring has been installed and should give valuable information on who accesses the site when and for how long.

There is no doubt that this type of new pedagogic tool will undergo a hefty development in the next years since it allows the students to learn the subjects according to their own pace and taking into account their previous education. If the project can be conducted as planned, teaching in small groups (either face-to-face with an assistant in exercise sessions, or through online monitoring) will considerably improve the teaching efficiency. Moreover, one may hope that other universities will join the project so that the site will become a real attraction for Swiss and foreign learners.

Received: January 23, 2003

\section{Acknowledgements}

The authors thank the Federal Office for Science and Technology, the Swiss University Council, the Swiss Virtual Campus as well as their own institutions (UNIL, EPFL, UNIGE, UNINE, UNIFR) for financial support. They are also grateful to Dr Jacques Viens (TECFA), Dr Bahram Zaerpour, Alessandro Anzani, Mylène Ducrey, Karim Vouilloz, Hervé Julien Camille Bierens de Haan (CENTEF), and D. Baumann (ICMB) who helped develop one aspect or the other of this project.

[1] Although the University of Lausanne is still the leading house of the project, the project leader has been transferred to the EPFL on October 1, 2001, as a result of the re-organization of the higher education institutions located on the shores of Lake Geneva.

[2] Out of 214 answers (questionnaire distributed in Lausanne on December 6, 2002), only $4 \%$ of learners have no computer; regarding their skill in computer use, 27\% state low-level practice, $57 \%$ an average level, and $15 \%$ an excellent level. Only $2 \%$ have no interest in participating in online teaching while $40 \%$ are very satisfied with the proposed website. On the other hand, only $22 \%$ have already taken part in a forum. 